\title{
Comparative uptake studies on trivalent f-cations from acidic feeds using two extraction chromatography resins containing a diglycolamide in molecular diluent and ionic liquid
}

\author{
Rajesh B. Gujar ${ }^{\mathrm{a}}$, Akalesh G. Yadav ${ }^{\mathrm{b}, \mathrm{c}}$, Prasanta K. Mohapatra ${ }^{\mathrm{a}, \mathrm{b}, *}$, T.P. Valsala ${ }^{\mathrm{c}}$, \\ Darshan B. Sathe ${ }^{c}$, Raj B. Bhatt ${ }^{c}$, Willem Verboom ${ }^{\mathrm{d}, *}$ \\ ${ }^{a}$ Radiochemistry Division, Bhabha Atomic Research Centre, Trombay, Mumbai-400085, India \\ ${ }^{\mathrm{b}}$ Homi Bhabha National Institute, Anushakti Nagar, Mumbai-400094, India \\ ${ }^{\mathrm{c}}$ Advanced Fuel Fabrication Facility, Nuclear Recycles Board, Tarapur, Maharashtra-401502, India \\ ${ }^{\mathrm{d}}$ Laboratory of Molecular Nanofabrication, MESA+ Institute for Nanotechnology, University of Twente, P.0. Box 217, 7500 AE Enschede, The Netherlands
}

\section{A R T I C L E I N F O}

\section{Article history:}

Received 3 December 2020

Revised 8 February 2021

Accepted 8 February 2021

Available online 12 February 2021

\section{Keywords:}

Diglycolamide

Extraction chromatography

Europium(III)

Ionic liquid

\begin{abstract}
A B S T R A C T
Low molecular weight diglycolamide (DGA) extractants were tested for the extraction of europium(III) and americium(III) from nitric acid solutions in n-dodecane, a molecular diluent and 1-butyl-3methylimidazolium bis(trifluoromethanesulphonyl) imide $\left(\mathrm{C}_{4} \mathrm{mim} \cdot \mathrm{NTf}_{2}\right)$, a room temperature ionic liquid, as the diluents. $N, N, N^{\prime}, N^{\prime}$-tetra- $n$-butyl diglycolamide (TBDGA) was selected for extraction chromatography (XC) studies involving $\mathrm{Eu}(\mathrm{III})$ and $\mathrm{Am}(\mathrm{III})$. While the TBDGA resin containing $n$-dodecane gave reasonably high $K_{\mathrm{d}}$ values, that containing the ionic liquid showed higher Eu(III) uptake values. Compared to Eu(III), Am(III) was extracted by the resins to a lower extent. The loaded Eu(III) was back extracted from the resin using $0.05 \mathrm{M}$ EDTA solutions in a buffered medium containing $1 \mathrm{M}$ guanidine carbonate. Reusability studies indicated that, while the ionic liquid-based resin can be conveniently recycled five times with very marginal decrease in the percentage extraction values, there was a sharp decrease in the percent extraction after three cycles with the $n$-dodecane-based resin. The uptake data was fitted into different isotherm models and the results conformed to the Langmuir model. Based on the batch uptake studies, columns were prepared and the breakthrough as well as elution profiles were obtained. The elution profiles were found to be sharp without any significant tailing.
\end{abstract}

(c) 2021 Elsevier B.V. All rights reserved.

\section{Introduction}

In view of the limited supply of fossil fuels, there is a paradigm change in energy utilization policy worldwide leading to an increasing dependence on non-conventional energy resources including nuclear power. Nuclear power, however, has several drawbacks which includes effective remediation of the highly hazardous radioactive wastes [1]. Furthermore, treatment of effluents containing actinides such as uranium, plutonium, etc. (which are present in the spent fuel in significant quantities) is also one of the most challenging tasks. Separation of these actinides from acidic feeds has been carried out using a solvent extraction based separation method by tri- $n$-butyl phosphate (TBP) where $\mathrm{UO}_{2}{ }^{2+}$ and $\mathrm{Pu}^{4+}$ are extracted as neutral extracted species such as $\mathrm{UO}_{2}\left(\mathrm{NO}_{3}\right)_{2} \cdot 2 \mathrm{TBP}$ and

\footnotetext{
* Corresponding authors.

E-mail addresses: mpatra@barc.gov.in (P.K. Mohapatra), w.verboom@utwente.nl (W. Verboom).
}

$\mathrm{Pu}\left(\mathrm{NO}_{3}\right)_{4} \cdot 2 \mathrm{TBP}$ in a process called PUREX (Plutonium Uranium Redox EXtraction), which is adopted worldwide for spent fuel reprocessing [2]. The PUREX raffinate contains a host of radionuclides most of which decay over a period of 5-10 years. On the other hand, the presence of minor actinides such as americium and curium, with relatively long half lives (e.g., ${ }^{243} \mathrm{Am}$ : $t_{1 / 2}=7.4 \times 10^{4}$ y; ${ }^{245} \mathrm{Cm}: \mathrm{t}_{1 / 2}=8.5 \times 10^{4} \mathrm{y}$ ), pose long term hazards to the biota making the scientific world to develop efficient separation methods for their separation. Additionally, occasional accidents and fallouts from weapon testing have made it necessary to develop methods for the separation of minor actinides from the environmental samples. Along with the trivalent actinide ions, trivalent lanthanide ions (mostly the lighter ones) are also found in the spent fuel and have similar chemical properties [3].

In the past few decades, there have been attempts to develop extractants that can efficiently extract the trivalent minor actinide ions viz. Am(III) and $\mathrm{Cm}$ (III). Out of the phosphorous-based extractants, which were developed and tested in the later part of the last 
century, the most common ones are CMPO (carbamoylmethylphosphine oxide) [4], DIDPA (diisodecyl phosphoric acid) [5] and TRPO (trialkylphosphine oxide) [6]. However, increasing concern for the environment has led to the subsequent development of 'green' extractants such as malonamides [7] and diglycolamides [8] (DGAs) out of which the latter are more widely studied.

Extraction chromatography, which involves very little organic solvent, is considered an efficient 'green' separation technique with the advantages of both the solvent extraction and the ion exchange methods [9-11]. Diglycolamide extractants such as TODGA ( $N, N, N$, $N$ '-tetra- $n$-octyldiglycolamide) have been employed in extraction chromatography resin (ECR) for the efficient uptake of trivalent $f$-cations from acidic feeds [12-15]. It has been reported that extractants with lower alkyl chain substituents are more efficient than their higher homologs [16]. In view of this, it was of interest to understand the role of alkyl chain length (especially the lower ones such as methyl, ethyl and butyl) on the metal ion extraction efficiency. However, due to the aqueous solubility of the methyl and ethyl derivatives, it was thought of interest to study the butyl derivative, i.e., TBDGA ( $N, N, N^{\prime}, N^{\prime}$-tetra-n-butyldiglycolamide) for the uptake studies in this work. Though most of the published literature with TODGA as the extractant in the ECR do not contain any diluent, it was imperative to add diluents in the present study. Apparently, diluents can have some role in the metal ion extraction / separation. Hence, an ECR containing TBDGA in n-dodecane was used in this study for the metal ion uptake studies.

Recently, room temperature ionic liquids have been proposed as alternative to the commonly used molecular diluents such as $n$-dodecane in solvent extraction-based separation studies on the basis of their superior properties such as non-flammability, wide electrochemical window, negligible vapor pressure, etc. [1722]. Out of the different ionic liquids studied of late, the ones with an imidazolium group and a bis-triflimide counter anion are found to be most widely investigated [18-22]. Also, out of the imidazolium-based bis-triflimide ionic liquids, the very often studied one is $\mathrm{C}_{4}$ mim. $\mathrm{NTf}_{2}$ (1-butyl-3-methylimidazolium bis(trifluoromethanesulfonyl)imide) probably due to very high extractions reported based on a cation-exchange mechanism [1822]. Therefore, another ECR containing TBDGA and $\mathrm{C}_{4} \mathrm{mim} \cdot \mathrm{NTf}_{2}$ was prepared and used for the uptake studies. Studies on ECRs containing an analogous ligand, $N, N$,-dioctyldiglycolamic acid, in $\mathrm{C}_{4} \mathrm{mim} \cdot \mathrm{NTf}_{2}$ has been used for the separation of ${ }^{225} \mathrm{Ac}$ in a recent report [23].

The present studies involved the uptake of $\mathrm{Eu}(\mathrm{III})$, taken as a surrogate of trivalent actinides and lanthanides, by the TBDGA based ECRs from acidic feed solutions. In selected cases, the uptake of Am(III) was also studied for comparison purpose. Similarly, in selected cases, the solvent extraction studies were carried out using TODGA and TBDGA in both n-dodecane and $\mathrm{C}_{4} \mathrm{mim} \cdot \mathrm{NTf}_{2}$. Both batch as well as column studies were carried out. Column studies were not performed with Am due to large radioactive dose to the working personnel. To our knowledge, this is the first ever report on a comparative evaluation of ECRs containing the lower homolog DGA ligands in a molecular diluent and ionic liquid for the uptake of trivalent lanthanides and actinides.

\section{Experimental}

\subsection{Reagents}

TBDGA was synthesized as reported previously [24]. The extractant was characterized by elemental analysis, NMR $\left({ }^{1} \mathrm{H}\right.$ NMR $\left(400 \mathrm{MHz}, \mathrm{CDCl}_{3}\right): \delta 4.27\left(\mathrm{~s}, 4 \mathrm{H}, \mathrm{OCH}_{2}\right), 3.3-3.1\left(\mathrm{~m}, 8 \mathrm{H}, \mathrm{NCH}_{2}\right)$, 1.6-1.4 (m, 8H, $\left.\mathrm{NCH}_{2} \mathrm{CH}_{2}\right), 1.35-1.15\left(\mathrm{~m}, 8 \mathrm{H}, \mathrm{CH}_{2} \mathrm{CH}_{3}\right)$, 0.95$0.8\left(\mathrm{~m}, 12 \mathrm{H}, \mathrm{CH}_{3}\right)$ ) and HRMS (theoretical: 357.3112, found: 357.3309). TODGA was obtained from Thermax Ltd with >98\% pu- rity. The diluents, $n$-dodecane and 1-butyl-3-methylimidazolium bis(trifluoromethanesulphonyl) imide $\left(\mathrm{C}_{4} \mathrm{mim} \cdot \mathrm{NTf}_{2}\right)$, were obtained from Lancaster, UK and IoliTech, Germany, respectively, and were used without further purification. Both EDTA (ethylenediamine- $N, N, N, N$ '-tetraacetic acid) and guanidine carbonate were procured from Sigma-Aldrich, USA. Suprapur nitric acid (Merck) was used for the preparation of $\mathrm{HNO}_{3}$ solutions, where dilutions were done with Milli-Q water (Millipore, USA). Chromosorb-W (dimethyl dichlorosilane treated acid washed celite diatomaceous silica, particle size: 180-250 micron) obtained from Johns Manville, USA was washed with distilled water, methanol and acetone, followed by air-drying before use. A standard $\mathrm{Eu}\left(\mathrm{NO}_{3}\right)_{3}$ solution was prepared by dissolving a known quantity of $\mathrm{Eu}\left(\mathrm{NO}_{3}\right)_{3} \cdot 6 \mathrm{H}_{2} \mathrm{O}$ (Sigma Aldrich) in $0.01 \mathrm{M}$ nitric acid followed by its volumetric titration with standard EDTA [25].

\subsection{Radiotracer}

${ }^{152,154} \mathrm{Eu}$ radiotracer was procured from BRIT (Board of Radiation and Isotope Technology), Mumbai in $0.1 \mathrm{M} \mathrm{HCl}$ solution and was used after checking its radiochemical purity by an HPGe detector. The radiometric assay of the uptake experiment samples containing ${ }^{152,154} \mathrm{Eu}$ radiotracer was carried out by gamma-ray counting of the multiple peaks in the energy range of $123 \mathrm{keV}$ to 1274 keV using a well type $\mathrm{NaI}(\mathrm{Tl})$ scintillation detector (Para Electronics) coupled to a multi-channel analyzer (ECIL, India).

\subsection{Preparation of the extraction chromatography resin (ECR)}

A known amount of TBDGA with the required amount of the diluent was equilibrated with a weighed quantity of Chromosorb$\mathrm{W}$ in excess of acetone taken in a stoppered conical flask for $24 \mathrm{~h}$ in a mechanical vortex mixer as described in an earlier report [26]. Chromosorb W was used in some of our previous studies [26] and was found to be quite satisfactory as the solid support material and hence, was used in this study. Typically, ca. $722 \mathrm{mg}$ of TBDGA and ca. $405 \mathrm{mg}$ of the diluent (either $n$-dodecane or the ionic liquid) were added to ca. $2 \mathrm{~g}$ of Chromosorb $\mathrm{W}$ and $20 \mathrm{~mL}$ of acetone. After equilibration, the acetone was removed by slow evaporation by flushing high purity nitrogen gas with gentle swirling of the conical flask. After removing almost the entire part of the solvent, the resultant DGA ligand loaded Chromosorb W resins were vacuum dried in a desiccator until the attainment of constant weights. Subsequently, they were used for the uptake studies by batch as well as column modes.

\subsection{Resin characterization}

The ECRs (extraction chromatography resins) were characterized by techniques such as FTIR, TGA (thermogravimetric analysis), SEM and EDX (energy dispersive X-ray spectroscopy). FTIR spectra of the solid samples were recorded on a Bruker Alpha II ATR-FTIR spectrometer. Thermogravimetric analysis was performed using a Netzsch Thermobalance (Model: STA 409 PC Luxx) at a heating rate of $5{ }^{\circ} \mathrm{C}$ per minute in air atmosphere up to $1000^{\circ} \mathrm{C}$ and the changes were correlated to the mass loss of the particular component. A stereoscan 100 Cambridge model SEM instrument was used for the surface morphology analysis. The instrument was operating at $15 / 25 \mathrm{kV}$ with a magnification of $3000 \mathrm{X}$ at a working distance of $15 \mathrm{~mm}$ at a tilt angle of $45^{\circ}$. The sample was given a $15 \mathrm{~nm}$ of gold coating using a Balzer's coating unit (model: CEA 30).

\subsection{Solvent extraction studies}

The solvent extraction studies were carried out by equilibrating $1 \mathrm{~mL}$ each of the organic (n-dodecane or ionic liquid) and the 
aqueous phases in leak tight stoppered Pyrex glass tubes in a thermostated water bath at $25 \pm 0.1^{\circ} \mathrm{C}$ for ca. 2 hours (this time was optimized by a preliminary experiment whose results are not included here) at $25 \mathrm{rpm}$ in a vertical direction. Subsequently, the tubes were centrifuged, phases separated and $100 \mu \mathrm{L}$ aliquots were taken out for radiometric assay of ${ }^{241} \mathrm{Am}$ or ${ }^{152,154} \mathrm{Eu}$ by gamma ray spectrometry. The distribution ratio (D) values were defined as the counts per unit time per unit volume in the organic phase by the same in the aqueous phase. The separation factor (SF) was defined as the ratio of $D_{E u}$ to $D_{A m}$.

\subsection{Uptake studies by the ECRs}

The solid phase extraction studies were carried out following a standard method where the aqueous phase contained tracer $\left({ }^{152,154} \mathrm{Eu}\right.$ and $\left.{ }^{241} \mathrm{Am}\right)$ spiked nitric acid solutions prepared from Suprapur nitric acid (vide supra). Leak tight Pyrex glass tubes (capacity $10 \mathrm{~mL}$ ) were used for the batch uptake studies where each tube, containing a known amount of the ECR (ca. 10-20 mg), was equilibrated with the required volume (usually 1-2 $\mathrm{mL}$ ) of the aqueous feed solution in a thermostated water bath at $25 \pm 0.1$ ${ }^{\circ} \mathrm{C}$. The tubes were subsequently centrifuged for about 2 minutes and rested for 5 minutes for the resin particles to settle down. The aqueous phase was carefully removed into a separate tube, followed by a fresh cycle of centrifugation and resting to completely rule out the presence of floating particles which could affect the assaying. In select cases, the solution was passed through 0.45 micron syringe filters and the close matching of the results by the two methods have validated our method above. Subsequently, about $50 \mu \mathrm{L}$ aliquots were removed for radiometric assay by $\gamma$-ray counting (vide supra). The weight distribution coefficient $\left(K_{\mathrm{d}}\right)$ was calculated using Eq. (1):

$K_{d}=\left[\frac{\left(C_{O}-C\right)}{C}\right] \cdot \frac{V}{W}$

where the final and initial concentration of the cation are given by $C$ and $C_{0}$, respectively, in the liquid phase (with volume ' $V$ ') in equilibrium with ' $W$ ' gram of the ECR.

The kinetic modeling studies were carried out by contacting the aqueous phase containing ${ }^{152,154} \mathrm{Eu}$ radiotracer at varying time intervals, while the sorption isotherm studies were carried out by taking varying amounts of the Eu carrier in the aqueous phase spiked with the radiotracer. The obtained data were fitted to pseudo-first order or pseudo-second order kinetic models, while the isotherm data were fitted to the Langmuir, Freundlich and D-R isotherm models.

All distribution measurements were done in triplicate and the accepted data were within $5 \%$ of standard deviation. A similar method was followed for the back extraction studies with the difference that the ${ }^{152,154} \mathrm{Eu}$ loaded ECR was used as the solid phase (with at least $5 \times 10^{6} \mathrm{cpm}$ per $\mathrm{g}$ of the resin) in combination with the required stripping solution (vide infra).

\subsection{Back extraction and reusability studies}

The batch back extraction studies were carried out by contacting the loaded resin (ca. $20 \mathrm{mg}$ ) containing the ${ }^{152,154} \mathrm{Eu}$ radiotracer (after the uptake as mentioned above) with the stripping solution (a mixture of $0.05 \mathrm{M}$ EDTA in $1 \mathrm{M}$ guanidine carbonate solution). The reusability studies were carried out by carefully recovering the regenerated resin (after back extraction of the loaded radiotracer) and giving fresh contact with a aqueous solution containing the radiotracer at $3 \mathrm{M} \mathrm{HNO}_{3}$.
Table 1

The solvent extraction data for $\mathrm{Am}^{3+}$ and $\mathrm{Eu}^{3+}$ using solutions of TODGA and TBDGA in $n$-dodecane and $\mathrm{C}_{4} \mathrm{mim} \cdot \mathrm{NTf}_{2}$.

\begin{tabular}{|c|c|c|c|c|}
\hline Extraction system $^{a}$ & Aqueous phase & $\mathrm{D}_{\mathrm{Am}}$ & $\mathrm{D}_{\mathrm{Eu}}$ & $\mathrm{SF}\left(\mathrm{D}_{\mathrm{Eu}} / \mathrm{D}_{\mathrm{Am}}\right)$ \\
\hline TODGA in $n$-dodecane & $1 \mathrm{M} \mathrm{HNO}_{3}$ & 0.05 & 0.36 & 7.2 \\
\hline TODGA in $n$-dodecane & $3 \mathrm{M} \mathrm{HNO}_{3}$ & 28.5 & 193 & 6.8 \\
\hline TODGA in $\mathrm{C}_{4} \mathrm{mim} \cdot \mathrm{NTf}_{2}$ & $1 \mathrm{M} \mathrm{HNO}_{3}$ & 803 & 721 & 0.90 \\
\hline TODGA in $\mathrm{C}_{4} \mathrm{mim} \cdot \mathrm{NTf}_{2}$ & $3 \mathrm{M} \mathrm{HNO}_{3}$ & 5.29 & 5.04 & 0.95 \\
\hline TBDGA in $n$-dodecane & $1 \mathrm{M} \mathrm{HNO}_{3}$ & 0.003 & 0.004 & 1.33 \\
\hline TBDGA in $n$-dodecane & $3 \mathrm{M} \mathrm{HNO}_{3}{ }^{\mathrm{b}}$ & 206 & 234 & 1.14 \\
\hline TBDGA in $\mathrm{C}_{4} \mathrm{mim} \cdot \mathrm{NTf}_{2}$ & $1 \mathrm{M} \mathrm{HNO}_{3}$ & 366 & 591 & 1.61 \\
\hline TBDGA in $\mathrm{C}_{4} \mathrm{mim} \cdot \mathrm{NTf}_{2}$ & $3 \mathrm{M} \mathrm{HNO}_{3}$ & 245 & 343 & 1.40 \\
\hline
\end{tabular}

a $0.014 \mathrm{M}$ solutions were used

b Third phase formation was observed.

\subsection{Column studies}

Two glass columns of ca. $4 \mathrm{~mm}$ diameter fused to a $15 \mathrm{~mL}$ beaker at the top (to hold the loading / elution solutions) were used for this purpose and about $500 \mathrm{mg}$ of the resins were packed inside the column by a slurry method. The resins were kept in a $25 \mathrm{~mL}$ beaker containing $10 \mathrm{~mL}$ water and the slurry was loaded slowly by ensuring that no air bubble was trapped inside the resin bed. For the breakthrough studies, the resin filled columns were first conditioned by passing about 10 bed volumes of $3 \mathrm{M} \mathrm{HNO}_{3}$. Subsequently, the feed solution was passed slowly at a flow rate of $0.05 \mathrm{~mL}$ per minute to obtain the breakthrough profiles with both the resins. The feed solution consisted of $1.2 \mathrm{~g} / \mathrm{L}$ Eu-nitrate solution in $3 \mathrm{M} \mathrm{HNO}_{3}$ which was spiked with ${ }^{152,154} \mathrm{Eu}$ radiotracer.

\section{Results and discussion}

\subsection{Solvent extraction studies}

Prior to the uptake studies using the two extraction chromatographic resins mentioned above, it was intended to carry out solvent extraction studies for comparative evaluation of the diluents, i.e., n-dodecane and $\mathrm{C}_{4} \mathrm{mim} \cdot \mathrm{NTf}_{2}$. Also, the extraction of $\mathrm{Eu}(\mathrm{III})$ and Am(III) was studied to get an idea about the separation factor values. Finally, TBDGA data were compared with the data obtained from experiments carried out using TODGA under identical conditions. The extraction of $\mathrm{Eu}(\mathrm{III})$ and $\mathrm{Am}(\mathrm{III})$ was negligible $(<0.001)$ with the diluents (n-dodecane and $\mathrm{C}_{4} \mathrm{mim} \cdot \mathrm{NTf}_{2}$ ) when used without the extractants such as TODGA / TBDGA. The solvent extraction results obtained with the solvents containing TODGA / TBDGA are presented in Table 1 . The extraction of both $\mathrm{Am}$ (III) and $\mathrm{Eu}(\mathrm{III})$ were very low at $1 \mathrm{M} \mathrm{HNO}_{3}$ when n-dodecane was used as the diluent while very high $\mathrm{D}$ values were obtained when the ionic liquid was used as the diluent. Secondly, the $\mathrm{D}$ values were higher for TBDGA at $3 \mathrm{M} \mathrm{HNO}_{3}$ than those obtained with TODGA for the n-dodecane based solvent system, though some haziness was seen for the former indicating partial third phase formation. Thirdly, the $\mathrm{D}$ values decreased significantly in the ionic liquid based solvent systems while increasing the aqueous phase acidity from $1 \mathrm{M}$ to 3 $M$ though it was quite drastic for TODGA as compared to TBDGA which may be attributed to the cation exchange mechanism.

The separation of lanthanides from trivalent minor actinides is one of the main issues in the back end of the fuel cycle in the 'actinide partitioning' step $[27,28]$. Most of the research in this area is focused on studying the relative separation of Am (the representative trivalent actinide element) and Eu (the representative trivalent lanthanide element present in radioactive wastes). As seen in a literature report [29], many of the extractants do not yield good separation factors between Am(III) and Eu(III) on account of their very similar chemical properties. However, TODGA, the most stud- 
Table 2

Resin preparation details for the DGA ligands in $n$-dodecane as well as ionic liquid along with the Eu(III) uptake data (expressed as $K_{\mathrm{d}}$ ) from $3 \mathrm{M} \mathrm{HNO}_{3}$.

\begin{tabular}{llllll}
\hline Solvent system & Ligand weight $(\mathrm{mg})$ & Ligand taken (millimoles) & Ligand loading $^{a}$ & Solvent loading $^{b}$ & $K_{\mathrm{d}}{ }^{c}$ \\
\hline TBDGA-DD & 361.1 & 1.014 & $23.1 \%$ & $36.1 \%$ & $28265( \pm 1205)$ \\
TBDGA-IL & 361.5 & 1.015 & $23.1 \%$ & $36.0 \%$ & $49071( \pm 2154)$ \\
\hline
\end{tabular}

a Calculated as the weight per cent ligand in the resin

b Calculated as the weight per cent solvent (ligand + diluent) in the resin

c Average of three measurements.

ied DGA extractant, is reported to have a separation factor (ratio of the distribution ratio values of $\mathrm{Eu}(\mathrm{III})$ and $\mathrm{Am}(\mathrm{III})$ ) value of ca. 10 at $1 \mathrm{M} \mathrm{HNO}_{3}$ [29]. We have studied the solvent extraction behavior of $\mathrm{Am}(\mathrm{III})$ and $\mathrm{Eu}(\mathrm{III})$ using TODGA as well as TBDGA at ca. 0.01 $\mathrm{M}$ concentrations using both $n$-dodecane as well as $\mathrm{C}_{4} \mathrm{mim} \cdot \mathrm{NTf}_{2}$ as the diluent (vide supra) and found the results with DBDGA quite encouraging in terms of extraction efficiency. While the SF (separation factor, defined as $D_{E u} / D_{A m}$ ) values were significantly higher (ca. 7) with TODGA - n-dodecane as the solvent system as compared to those obtained for TBDGA (ca. 1), the selectivity seen in case of TODGA was lost when the ionic liquid was used as the diluent. Careful observation of the solvent extraction data (Table 1) suggested that while the $\mathrm{Eu}^{3+}$ ion was preferentially extracted (as compared to $\mathrm{Am}^{3+}$ ) in the TODGA in $n$-dodecane solvent, a reversal $\left(\mathrm{Am}^{3+}\right.$ ion was better extracted than the $\mathrm{Eu}^{3+}$ ion) was seen in TODGA in $\mathrm{C}_{4} \mathrm{mim} \cdot \mathrm{NTf}_{2}$ as the solvent. On the other hand, $\mathrm{Eu}^{3+}$ was better extracted in the TBDGA in $\mathrm{C}_{4} \mathrm{mim} \cdot \mathrm{NTf}_{2}$ solvent. In the ionic liquid medium, a cation-exchange type mechanism is followed [19,21], which was reflected in a decrease in metal ion extraction with increasing $\mathrm{HNO}_{3}$ concentration while a solvation type extraction mechanism was seen for the solvent containing $n$ dodecane where an increase in the $D$ values was seen with increasing the aqueous phase nitric acid concentration.

\subsection{Extraction chromatography studies}

The resin beads, prepared by the above-mentioned method, were found to be free flowing. A summary of the loading of the resin material with ligand and solvent is given in Table 2. The TBDGA resins were characterized as given in the following section and were used for subsequent batch uptake and column studies which included generation of breakthrough curves and also of loading and elution profiles of Eu(III) solutions in dilute acid conditions.

\subsubsection{Characterization of the resins}

The resin beads were characterized by different techniques such as FTIR, for the presence of the extractant, thermogravimetric analysis (TGA), for confirming the ligand / solvent loading and SEM, for surface morphology. As seen from the TGA curves of the two TBDGA-containing resins (Fig. 1), the \% weight loss was ca. $27 \%$ and $35 \%$ for the resins containing $n$-dodecane and the ionic liquid, respectively.

One would expect ca. 36\% weight loss for both the TBDGA resins (Table 2) assuming that there is no diluent loss (n-dodecane or ionic liquid) from the resins during vacuum drying. On the other hand, the extractant (TBDGA) loading is ca. $23 \%$ for both the resins. Fig. 1a shows that the TBDGA - $n$-dodecane resin displays a weight loss of ca. $27 \%$, suggesting the burning of the entire amount of the extractant (23\%) and a very small amount of the diluent (ca. $4 \%$ ) in the temperature range of $180-260{ }^{\circ} \mathrm{C}$. The balance amount of $n$-dodecane can be attributed to evaporation loss during vacuum drying. On the other hand, Fig. 1b exhibits that the TBDTA - IL resin shows a total weight loss of ca. $35 \%$, which accounts for both the ligand and the ionic liquid, used as the diluent. While the ligand decomposition is gradual and is probably complete at $260{ }^{\circ} \mathrm{C}$, the decomposition of the ionic liquid is complete only after $470{ }^{\circ} \mathrm{C}$. The decomposition of resins containing only TBDGA, n-dodecane or the ionic liquid was also studied and the results are shown in the supporting information. As shown, n-dodecane was easily removed and explains the lesser weight loss of the TBDGA-n-dodecane resin as the $n$-dodecane might have partially escaped during the vacuum drying process itself.

The FTIR spectra of both the resins are recorded and given in the supporting information. The $>\mathrm{C}=\mathrm{O}$ functional groups, characteristic of the TBDGA extractant, are clearly identifiable from the bands in the range of $1650 \mathrm{~cm}^{-1}$. The presence of a very small amount of moisture is reflected as the broad band centered around $3470 \mathrm{~cm}^{-1}$. The three bands in the range of $2870-2960 \mathrm{~cm}^{-1}$ represent the $\mathrm{C}-\mathrm{H}$ bonds present in the butyl group of the extractant. The alkyl groups in the diluent, $n$-dodecane or ionic liquid, also can give rise to bands in the same region. The $\mathrm{NTf}_{2}{ }^{-}$group of the ionic liquid gives a band in the range of $650-660 \mathrm{~cm}^{-1}$, which is attributed to the S-N-S bending mode [30], while the S-N$\mathrm{S}$ asymmetric stretching band comes around $1058 \mathrm{~cm}^{-1}$ [31]. The $\mathrm{S}-\mathrm{O}$ stretch is expected at around $1150 \mathrm{~cm}^{-1}$. The two peaks at $3105 \mathrm{~cm}^{-1}$ and $3152 \mathrm{~cm}^{-1}$ refer to the $\mathrm{C}-\mathrm{H}$ stretching bands in the imidazolium ring [32]. A careful observation of the FTIR spectra (supporting information) confirms the presence of the ionic liquid inside the resin pores.

The SEM pictures of both the resins are presented in Fig. 2 at two different magnifications. The morphology appears similar for both the resins suggesting similar coating of the extractants. Furthermore, the honeycomb like structures can be seen at higher magnification, which is responsible for the holding of the extractant molecules inside the resin pores. As discussed below, this also may be the factor responsible for the faster kinetics of uptake.

\subsection{Batch uptake studies}

The batch uptake efficiency of the resins was studied by equilibrating a known amount of the resin with an ${ }^{152,154} \mathrm{Eu}$ tracer spiked aqueous acid solution ( $3 \mathrm{M} \mathrm{HNO}_{3}$ ) and determining the $K_{\mathrm{d} \text {,Eu }}$ values (vide supra). As shown in Table 2, both the TBDGAbased resins displayed very high $K_{\mathrm{d}}$ values. Detailed results of the uptake studies are given below. In general, the resin containing ionic liquid resulted in higher uptake of $\mathrm{Eu}(\mathrm{III})$ ion as compared to the resin containing $n$-dodecane.

\subsubsection{Optimization of equilibration time}

The uptake of $\mathrm{Eu}(\mathrm{III})$ from $3 \mathrm{M} \mathrm{HNO}_{3}$ was studied as a function of time and the results ( $\mathrm{K}_{\mathrm{d}}$ values) are presented in Fig. 3. The results suggest that the attainment of equilibrium (in terms of steady $K_{\mathrm{d}}$ values) takes ca. 20 minutes for both the TBDGA resins made in $n$-dodecane and the ionic liquid, the latter being marginally slower. Though ionic liquids are reported to have a slow attainment of equilibrium in solvent extraction studies [33], due to their relatively high viscosities $\left(\mathrm{C}_{4}\right.$ mim.NTf $\mathrm{N}_{2}$ has a viscosity of ca. $45 \mathrm{mPa} . \mathrm{s}$ at $298 \mathrm{~K}$ vis-à-vis that of ca. $1.34 \mathrm{mPa}$.s for n-dodecane) [34], no such slow attainment of equilibrium was seen in the present case. All subsequent studies, however, were carried out using $60 \mathrm{~min}-$ utes as the equilibration time for the sake of convenience. 

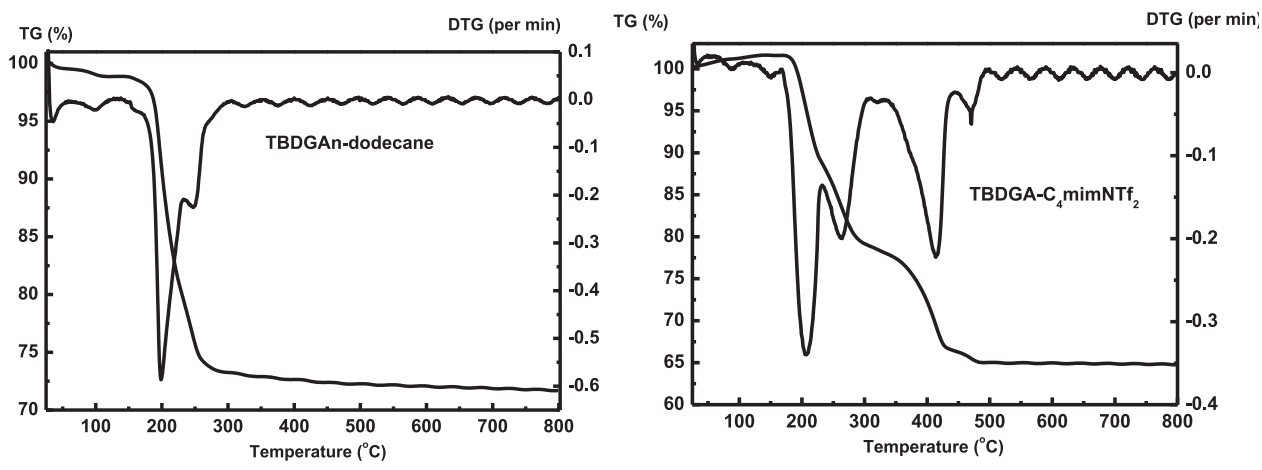

Fig. 1. TGA profiles of the resins containing TBDGA with (a) n-dodecane and (b) ionic liquid as the diluent.

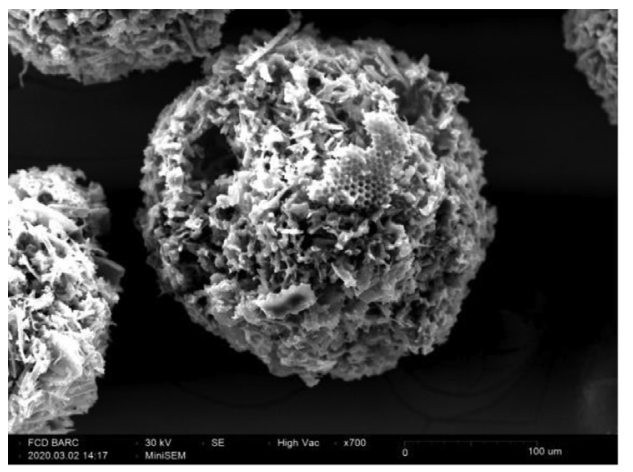

(a)

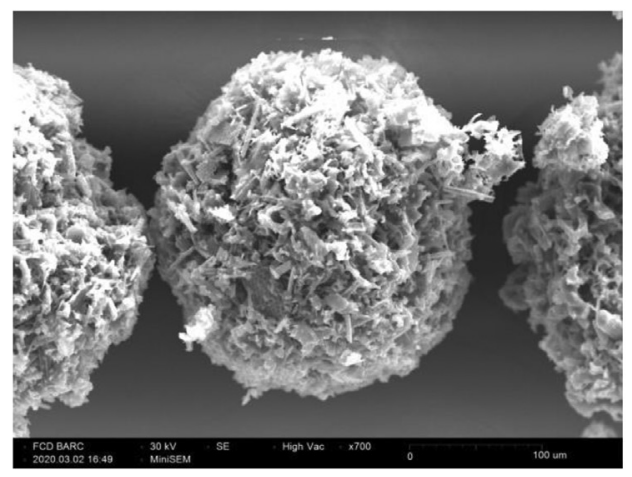

(c)

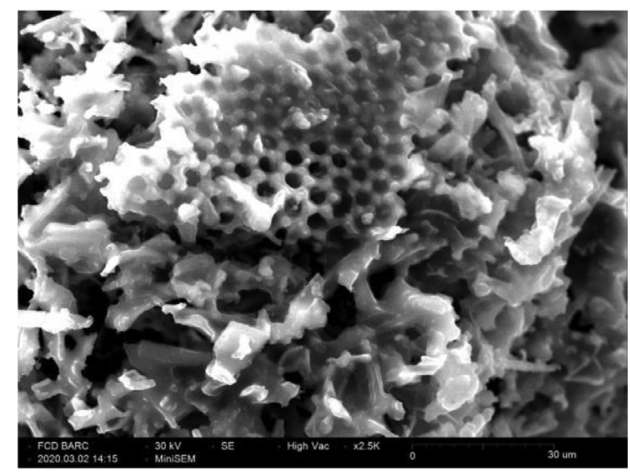

(b)

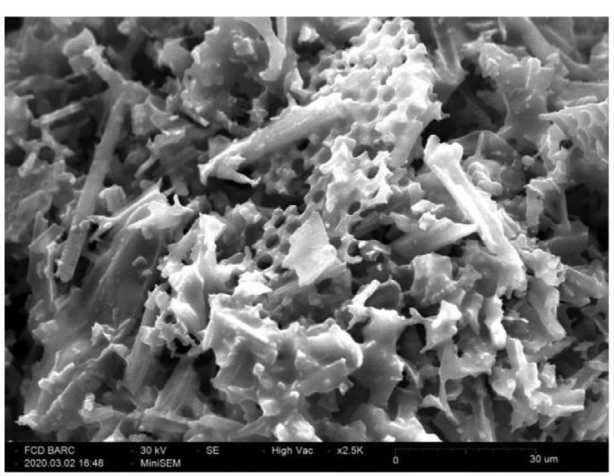

(d)

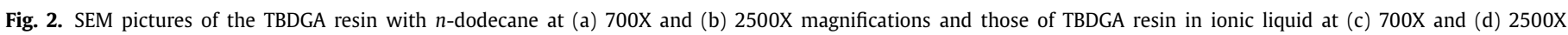
magnifications.

\subsubsection{Effect of feed acid concentration}

The uptake of the metal ions (in terms of the $\mathrm{K}_{\mathrm{d}}$ ) from any feed solution depends on the feed acid concentration. It is relevant to carry out the uptake of $\mathrm{Eu}(\mathrm{III})$ from a range of nitric acid solutions, viz. $0.01 \mathrm{M}-6 \mathrm{M}$, for application to the remediation of radioactive waste solutions. The results of the uptake studies, as expressed as the $K_{\mathrm{d}}$ values, are presented in Fig. 4. Two key observations are made from the figure, viz., i) $\mathrm{Eu}^{3+}$ is better extracted by the resins than $\mathrm{Am}^{3+}$; ii) ionic liquid based resins yielded higher $\mathrm{K}_{\mathrm{d}}$ values than the n-dodecane based resins. It is known that the extraction of $\mathrm{Eu}(\mathrm{III})$ is higher than that of $\mathrm{Am}(\mathrm{III})$ when DGA extractants are used [35]. In view of this, the uptake of Am(III) was also investigated under identical conditions for comparison purposes and the results are also presented in Fig. 4.

\subsubsection{Separation behavior}

The selectivity seen in case of the solvent extraction studies (vide supra), especially for the TODGA - $n$-dodecane solvent system was not observed with the ECRs. The separation factor $\left(\mathrm{SF}=K_{\mathrm{d}, \mathrm{Eu}} / K_{\mathrm{d}, \mathrm{Am}}\right)$ values are calculated at different acidities and the results are listed in Table 3. The uptake of $\mathrm{Eu}(\mathrm{III})$ was higher than that of Am(III) (vide supra). The relative separation behavior of the metal ions with TODGA and two multiple DGA extractant loaded ECRs was reported before. The results obtained with the resins containing these ligands are also included in Table 3 for comparison purpose, where T-DGA is a tripodal DGA extractant with a carbon center [36,37] and C4DGA is a calix[4]arene extractant with four DGA moieties substituted at the lower rim [36,37]. 


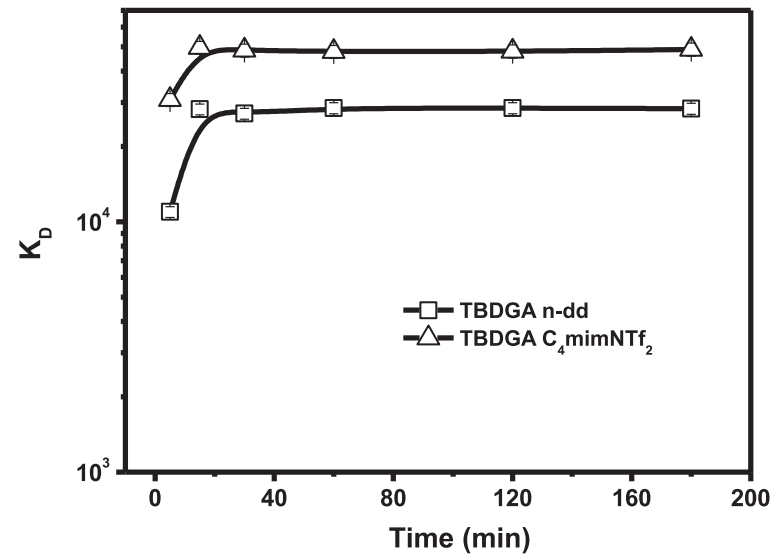

Fig. 3. Uptake of $\mathrm{Eu}(\mathrm{III})$ from $3 \mathrm{M}$ nitric acid using the extraction chromatography resins ( $\mathrm{n}$-dd $=n$-dodecane).

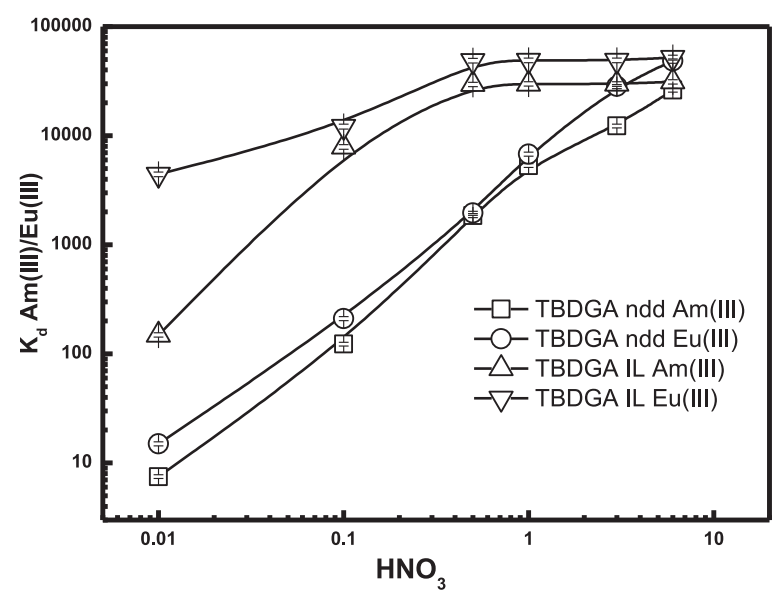

Fig. 4. Uptake of $\mathrm{Am}(\mathrm{III})$ and $\mathrm{Eu}(\mathrm{III})$ as a function of feed nitric acid concentration (n-dd =n-dodecane).

Table 3

Separation behavior of Am(III) and Eu(III) with DGA-loaded ECRs from 3 M nitric acid feed solutions.

\begin{tabular}{lllll}
\hline ECR & $K_{\mathrm{d}, \mathrm{Am}}$ & $K_{\mathrm{d}, \mathrm{Eu}}$ & SF & Ref. \\
\hline TODGA-IL $^{a, b}$ & 15785 & 18415 & 1.17 & {$[34]$} \\
TODGA $^{c, d}$ & 7212 & 9018 & 1.25 & {$[13]$} \\
T-DGA-IL $^{a, b}$ & 37210 & 50240 & 1.35 & {$[35]$} \\
T-DGA-DD $^{e, b}$ & 8335 & 9939 & 1.19 & {$[36]$} \\
C4DGA-IL $^{a, b}$ & 34680 & 37550 & 1.08 & {$[35]$} \\
C4DGA-DD $^{e, b}$ & 6985 & 8330 & 1.19 & {$[36]$} \\
TBDGA-IL $^{a, f}$ & $29,785 \pm 1,370$ & $49,071 \pm 2,453$ & $\sim 1.65^{g}$ & This work \\
TBDGA-DD $^{e, f}$ & $12,290 \pm 503$ & $28,265 \pm 1,215$ & $\sim 2.3^{g}$ & This work \\
\hline
\end{tabular}

\footnotetext{
a $\mathrm{IL}=$ ionic liquid ${ }^{b} 10 \%$ extractant loading

c No diluent was used hered

d $47 \%$ extractant loading

e $\mathrm{DD}=n$-dodecane

f $23 \%$ extractant loading

$\mathrm{g}$ Errors are ignored.
}

The separation factor values are ca. 1.65 and 2.3 for the IL- and $n$-dodecane-based ECRs, respectively (Table 3), suggesting that the two TBDGA resins (in $n$-dodecane and in the ionic liquid) are not as efficient as the solvent extraction system from the view point of metal ion separation as reported by Sasaki et al. during their solvent extraction studies [29]. However, when compared with other DGA-based extractants viz., TODGA, T-DGA or C4DGA, a superior separation efficiency was seen for both TBDGA resins. It is understood that the selectivity in case of the solvent extraction system using TODGA comes mainly from reverse micelle formation [38]. It

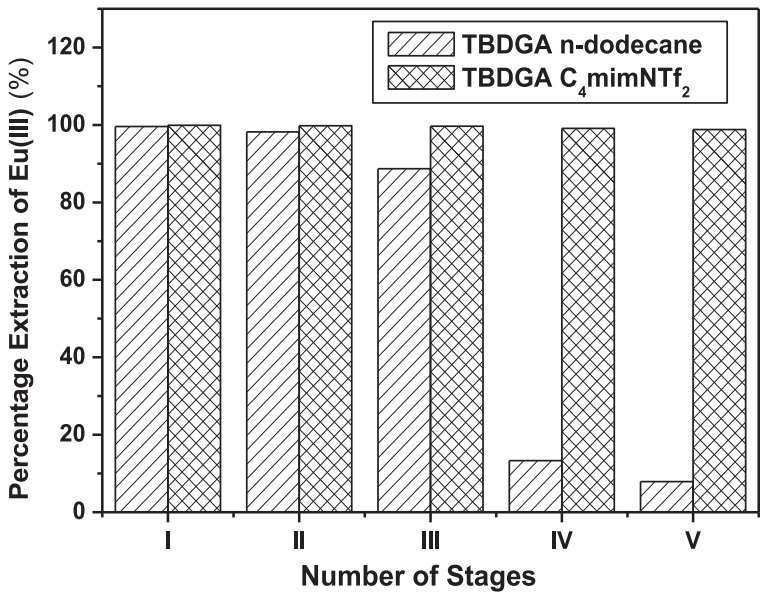

Fig. 5. Reusability data of the TBDGA - n-dodecane and TBDGA - ionic liquid resins; the uptake studies were carried out using ${ }^{152,154} \mathrm{Eu}$ tracer spiked $3 \mathrm{M}$ nitric acid as the feed.

is quite reasonable to assume that reverse micelle formation is not possible in the pores of a resin and hence, there is a loss of selectivity. However, in terms of uptake efficiency, the TBDGA resin is far superior to that of the reported resin with TODGA [13]. While a $47 \%$ TODGA-loaded resin yielded a $K_{\mathrm{d} \text {,Eu }}$ value of 9939 , the $37 \%$ TBDGA-loaded resin resulted in the same as 28,265. We could not compare the TODGA - IL resin data with that of the TBDGA - IL resin since the extractant loadings are not comparable. While a $10 \%$ TODGA-loaded IL resin resulted in a $K_{\mathrm{d}, \mathrm{Eu}}$ value of 18,415 [35], a value of 49,071 was obtained with the TBDGA loaded IL resin, albeit with a higher extractant loading (23\%), in the present study.

\subsubsection{Back extraction and reusability}

It was considered pertinent to assess the back extraction of the loaded Eu(III) onto the resin so that the ECR could be used for another uptake run. The stripping (or back extraction) was carried out using $0.05 \mathrm{M}$ EDTA in $1 \mathrm{M}$ guanidine carbonate solution, which regenerated the resin quite efficiently. This combination of the stripping solution was used in a previous study involving ionic liquid based solvents and was found to be quite efficient [39]. To assess the suitability of the resin for multiple use, the uptake and stripping cycle was repeated five times with both the resins, i.e., those containing TBDGA - $n$-dodecane and TBDGA - ionic liquid. The results are summarized in Fig. 5 which demonstrate a very efficient performance with the ionic liquid-based ECR. Fig. 5 exhibits that the \% uptake value for the ionic liquid-based resin was $99.9 \%$ after the first run, which remained very close to $99 \%$ throughout the five cycles, suggesting excellent reusability of the resin. On the other hand, the TBDGA - $n$-dodecane resin yielded a \% uptake value of $99.6 \%$ after the first run, which marginally decreased to $98.2 \%$ in the second run. However, the \% uptake value sharply decreased thereafter and an uptake value of only $7.9 \%$ was obtained during the $5^{\text {th }}$ run. This suggests that this molecular diluent-based resin has a limited reusability and one needs to opt for the ionic liquid-based resin if long term reusability of the resin is required for any actual application.

The Eu(III) uptake by the resin was established by energy dispersive X-ray spectroscopy (EDX), wherein the resins were loaded with macro concentrations of Eu(III), as the resins containing trace concentrations, the metal ion may be difficult to detect. The $\mathrm{Eu}(\mathrm{III})$ carrier solution contained $1.2 \mathrm{~g} / \mathrm{L} \mathrm{Eu}$ in $3 \mathrm{M} \mathrm{HNO}_{3}$. The EDX spectra are presented in the supporting information which clearly show the Eu peaks confirming the uptake of Eu(III) ions by both the TBDGA resins. 
Table 4

Linearized forms of different sorption isotherm model equations.

\begin{tabular}{llll}
\hline Model & Linearized form model equation $q_{\mathrm{e}}{ }^{a}$ & Plot & References \\
\hline Langmuir & $\frac{C_{e}}{q_{e}}=\frac{[1]}{b \cdot q_{\max }}+\frac{C_{e}}{q_{\max }}$ & $\frac{C_{e}}{q_{e}} v s \cdot C_{e}$ & {$[40]$} \\
Freundlich & $\log q_{e}=\log K_{f}+\frac{1}{n} \log C_{e}$ & $\log q_{e} v s \cdot \log C_{e}$ & {$[41]$} \\
D-R & $\ln q_{e}=\ln q_{\max }-\beta \varepsilon^{2}$ & $\ln q_{e} v s \cdot \varepsilon^{2}$ & {$[43]$} \\
Temkin & $q_{e}=B_{T} \ln A_{T}+B_{T} \ln C_{e}$ & $q_{e} v s \cdot \ln C_{e}$ & {$[42]$} \\
\hline
\end{tabular}

a $q_{\mathrm{e}}$ is the concentration of the metal ion (Eu(III)) sorbed per gram of the solid at equilibrium; $C_{\mathrm{e}}$ is the equilibrium concentration of metal ions in the aqueous phase; $q_{\mathrm{max}}$ and $K_{\mathrm{f}}$ are the maximum sorbed mass of $\mathrm{Eu}(\mathrm{III})$ at saturation.
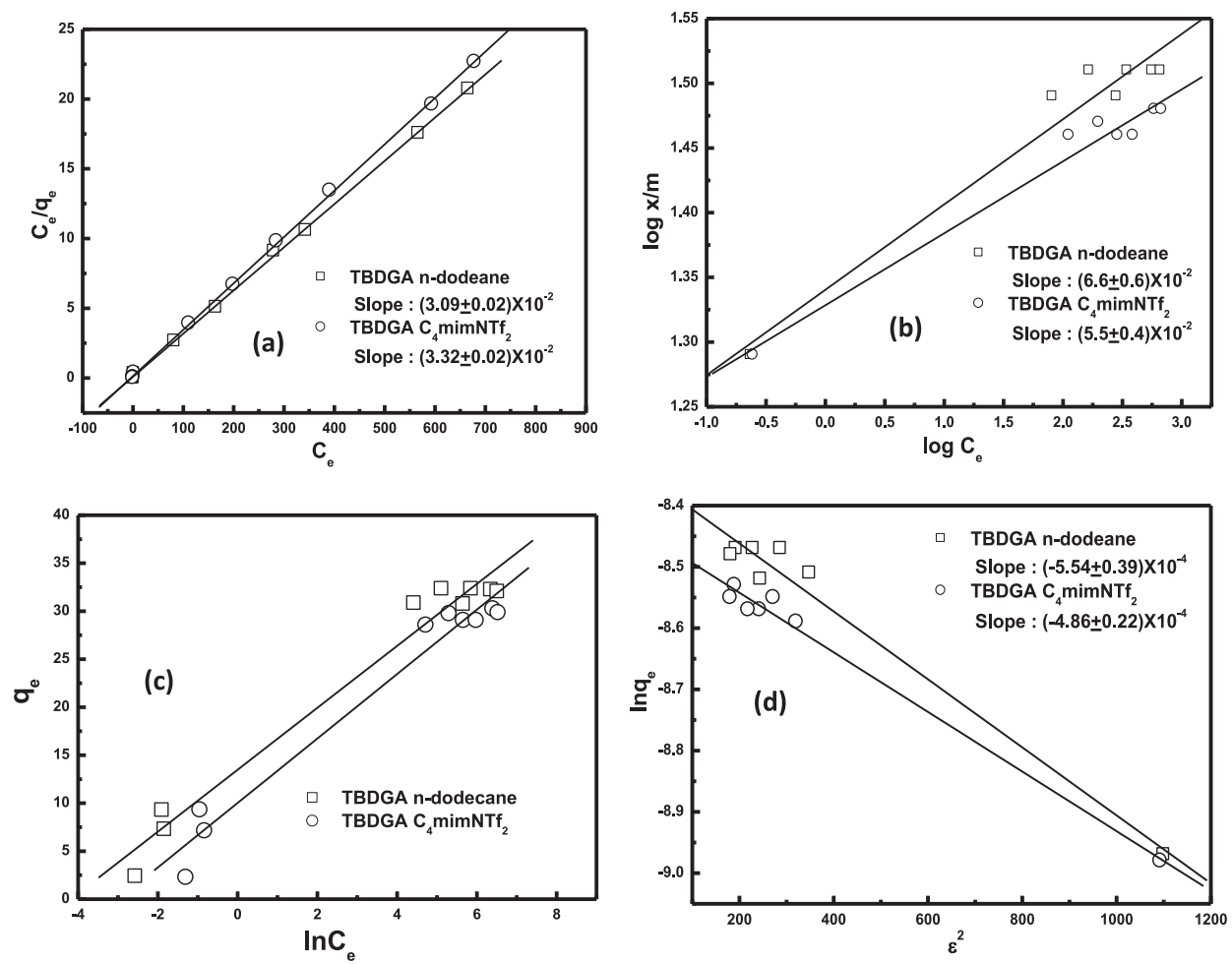

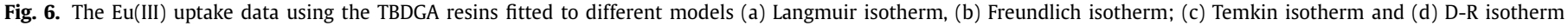

\subsubsection{Sorption isotherms}

Though the uptake of $\mathrm{Eu}(\mathrm{III})$ ion by both the TBDGA resins was quite efficient, it was important to understand the uptake or sorption mechanism. For this purpose, sorption isotherm studies were taken up using both the TBDGA resins. The Eu(III) sorption isotherm data were obtained at $3 \mathrm{M} \mathrm{HNO}_{3}$ using feed solutions containing varying amounts of the metal ion. The sorption data were analyzed critically by fitting the data in to the most widely used isotherm models, viz. Langmuir, Freundlich, DubininRadushkuvich (D-R) and Temkin. The linearized forms of these isotherm equations are given in Table 4.

The maximum uptake of $\mathrm{Eu}(\mathrm{III})$ by the resins using the batch uptake method was found out by equilibrating about $25 \mathrm{mg}$ of the resin with the feed solution, which contained $1.2 \mathrm{~g} / \mathrm{L}$ of $\mathrm{Eu}$ in 3 $\mathrm{M} \mathrm{HNO}_{3}$. The sorption isotherm data were fitted to various models and the plots are presented in Fig. 6. As shown in Fig. 6(a), the Langmuir plot of $C_{e} / q_{e} v s . C_{e}$ yielded a straight line fit with regression fitting parameters $\left(\mathrm{R}^{2}\right)$ as 0.998 for both the resins, suggesting that the sorption of Eu(III) obeys the Langmuir sorption monolayer model to a very large extent. The maximum $\mathrm{Eu}(\mathrm{III})$ sorption capacities (in $\mathrm{mg} / \mathrm{g}$ ) of the resins as obtained from the slope of the Langmuir plots are $32.4 \pm 1.31$ for the TBDGA - $n$-dodecane resin and $30.1 \pm 1.10$ for the TBDGA - ionic liquid resin (Table 4). The calculated $q_{\max }$ values obtained from the Langmuir model are in close agreement with the experimental values obtained in the batch experiments $(31.9 \pm 1.41$ for the TBDGA - $n$-dodecane resin; $29.8 \pm$ 1.20 for the TBDGA - ionic liquid resin). The maximum sorption capacity in the Langmuir model $\left(q_{\max }\right)$ indicates the monolayer coverage of the metal ions on the solid. A dimensionless equilibrium constant, $R_{L}$, expressed as:

$R_{L}=1 /\left(1+b C_{o}\right)$

where $C_{o}$ is the initial concentration of the metal ions, is used to evaluate the favourability of the Langmuir isotherm model [44]. The value of $R_{L}$ represents the sorption situation to be either unfavourable $\left(R_{L}>1\right)$, linear $\left(R_{L}=1\right)$, favourable $\left(0<R_{L}<1\right)$ or irreversible $\left(R_{L}=0\right)$. Considering the initial $\mathrm{Eu}(\mathrm{III})$ concentration as $1.2 \mathrm{mg} / \mathrm{mL}$, the values of $R_{L}$ for both the resins were calculated and were found to fall between 0 and 1, which confirms that the sorption of the metal ion onto the TBDGA resins as favourable.

Though the sorption isotherm fitting to the Langmuir model was very good, we attempted to fit the data into the Freundlich model, which assumes multilayer sorption of the metal ions on the resin surface. The plots of the fitted data to the Freundlich model $\left(\log \mathrm{x} / \mathrm{m}\right.$ vs $\left.\log C_{\mathrm{e}}\right)$ are presented in Fig. $6(\mathbf{b})$, which showed poor fitting of the data points, indicating that the multilayer sorption phenomenon may be absent in the present study. To support this outcome, we tried to fit the sorption data to the Temkin isotherm 
Table 5

Parameters calculated from Langmuir, Freundlich and D-R isotherm models for the sorption of Eu(III) on the TBDGA resins; Aqueous phase: $3 \mathrm{M}$ nitric acid.

\begin{tabular}{lll}
\hline Isotherms & Parameters & Values at $25^{\circ} \mathrm{C}$ \\
\hline \multirow{2}{*}{ Langmuir } & $\mathrm{b}(\mathrm{mL} / \mathrm{mg})$ & n-dodecane resin: 0.36 ; ionic liquid resin: 0.23 \\
& $q_{\max }(\mathrm{mg} / \mathrm{g})$ & n-dodecane resin: $32.4 \pm 1.31$; ionic liquid resin: $30.1 \pm 1.10$ \\
& $\mathrm{R}^{2}$ & n-dodecane resin: $0.998 ;$ ionic liquid resin: 0.998 \\
Freundlich & $\mathrm{K}_{\mathrm{f}}(\mathrm{mg} / \mathrm{g})$ & n-dodecane resin: $1.34 \pm 0.01$; ionic liquid resin: $1.32 \pm 0.01$ \\
& $\mathrm{n}$ & n-dodecane resin: 15.2 ; ionic liquid resin: 17.9 \\
& $\mathrm{R}^{2}$ & n-dodecane resin: $0.978 ;$ ionic liquid resin: 0.987 \\
$\mathrm{D}-\mathrm{R}$ & $q_{\max }(\mathrm{mmol} / \mathrm{g})$ & n-dodecane resin: $0.24 \pm 0.01$; ionic liquid resin: $0.22 \pm 0.02$ \\
& $\beta \times 10^{4}\left(\mathrm{~mol}^{2} \mathrm{~kJ}^{-2}\right)$ & n-dodecane resin: $-(5.5 \pm 0.2)$; ionic liquid resin: $-(4.8 \pm 0.1)$ \\
& & n-dodecane resin: $30.0 \pm 1.70$; ionic liquid resin: $32.1 \pm 1.81$ \\
& $E(\mathrm{~kJ} / \mathrm{mole}) \mathrm{R}^{2}$ & n-dodecane resin: $0.998 ;$ ionic liquid resin: 0.995 \\
& $\mathrm{~B}$ & n-dodecane resin: $3.22 \pm 0.20 ;$ ionic liquid resin: $3.36 \pm 0.23$ \\
& $\mathrm{~A}_{\mathrm{T}}$ & n-dodecane resin: $0.07 \pm 0.01$; ionic liquid resin: $0.02 \pm 0.01$ \\
& $\mathrm{R}^{2}$ & n-dodecane resin: $0.986 ;$ ionic liquid resin: 0.984
\end{tabular}

model (Table 4). This model considers the presence of indirect sorbate / sorbate interactions and suggests that because of these interactions the heat of sorption of all the molecules in the layer would decrease linearly with coverage. Fitting of the sorption data to the Temkin isotherm model would be indicating the presence of a multilayer sorption phenomenon. As seen from Fig. 6(c), the plots for the Temkin isotherm equation deviate from linearity, thereby confirming the absence of multilayer sorption in the present work, which is in line with the poor fitting of the uptake data to the Freundlich model. The Temkin model fitting parameters are also included in Table 5.

After this, the experimental data were also fitted to the D-R isotherm model (Table 4) to distinguish between physisorption and chemisorption, i.e., whether a chemical reaction is involved in the sorption process. The D-R isotherm is based on the postulate that if the surface is heterogeneous and the Langmuir isotherm is chosen as a local isotherm for all sites that are energetically equivalent, then the quantity $\beta$ can be correlated to the mean sorption energy as [45]:

$E=1 / \sqrt{-2 \beta}$

Here, the mean sorption energy $(E)$ is the free energy needed to transfer one mole of metal ions from infinity to the surface of the sorbent [44]. The mean sorption energy gives information about the type of sorption mechanism, chemisorption or physisorption [46]. The D-R constants $\beta$ and $q_{\max }$, obtained graphically (Fig. $6(\mathbf{d})$ ) are also listed in Table 5 . The $\mathrm{q}_{\max }$ values are given in $\mathrm{mmol} / \mathrm{g}$ which can be converted to 36.7 and $33.7 \mathrm{mg} / \mathrm{g}$, respectively. These values are somewhat larger than the $q_{\max }$ values obtained experimentally (vide supra). A value of $E>8 \mathrm{~kJ} / \mathrm{mol}$ signifies to a chemisorption process, whereas a value $<8 \mathrm{~kJ} / \mathrm{mol}$ points to a physical sorption process. The numerical values of $E$ in the present work were found to be $>8 \mathrm{~kJ} / \mathrm{mol}$ (Table 5), indicating that the sorption takes place via chemical interaction. Taking a clue from the solvent extraction studies reported before [47], the chemical reaction involved in the present case can be given as per the following equation:

$\mathrm{Eu}^{3+}{ }_{a q}+\mathrm{TBDGA}_{\mathrm{Resin}}+3 \mathrm{NO}_{3 \mathrm{aq}}^{-}=\mathrm{Eu}\left(\mathrm{NO}_{3}\right)_{3} \cdot \mathrm{TBDGA}_{\text {Resin }}$

where the species with the subscripts 'aq' and 'Resin' refer to those in the aqueous and the resin phases, respectively.

\subsection{Column studies}

To utilize the batch uptake data for possible application of the TBDGA-based resin materials, column studies were carried out. The various column parameters of the two TBDGA-based resins are given in Table 6 . The breakthrough profiles obtained with both

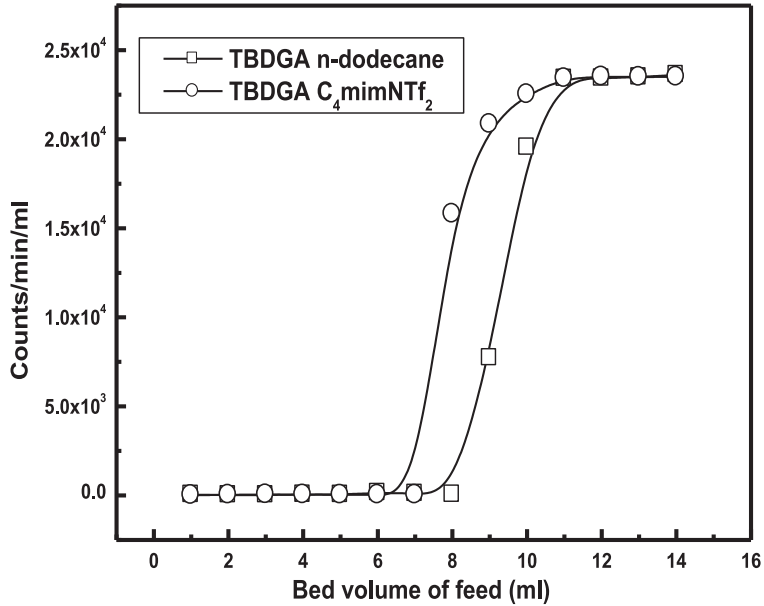

Fig. 7. Breakthrough profiles obtained with the TBDGA resins. Feed: $1.2 \mathrm{~g} / \mathrm{L} \mathrm{Eu}$ nitrate solution in $3 \mathrm{M}$ nitric acid.

the TBDGA resins are presented in Fig. 7 showing that the breakthrough of $\mathrm{Eu}(\mathrm{III})$ is after the passing of ca. $7 \mathrm{~mL}$ of the feed solution (mentioned above) through the TBDGA - ionic liquid resin based column. On the other hand, $8 \mathrm{~mL}$ was found to be the breakthrough volume when the TBDGA - n-dodecane resin column was used. The early breakthrough with the ionic liquid resin column is not properly understood as the $K_{\mathrm{d}}$ value obtained with this resin was significantly higher than that obtained with the $n$ dodecane-based resin. However, it is speculated that the uptake kinetics (which was marginally slower for the ionic liquid-based resin) may be responsible for this.

As mentioned in Table 6, the columns were prepared by packing ca. $0.5 \mathrm{~g}$ of the TBDGA resins, the total Eu loading to the resins was calculated to be $16.8 \mathrm{mg} / \mathrm{g}$ on the ionic liquid resin and 20.2 $\mathrm{mg} / \mathrm{g}$ on the $n$-dodecane resin. On the other hand, the batch studies indicated that 30.1 and $32.4 \mathrm{mg} / \mathrm{g}$ is the saturation uptake capacity of the ionic liquid and $n$-dodecane based resins, respectively. This means about $56 \%$ and $62 \%$ capacity utilization with the ionic liquid and $n$-dodecane resins, respectively. It is important to mention here that the loading capacity of the column is generally affected by the column bed height, flow rate and reaction kinetics between the metal ion and the ligand on the resin. The lower metal loading in the column in the present study may be assigned to relatively inefficient mass transfer rates in these resins. Apparently, a lower flow rate may be beneficial in increasing the column loading. In order to find out the effect of Eu loading on the $K_{\mathrm{d}}$ values, batch uptake studies were carried out using a feed containing $1.2 \mathrm{~g} / \mathrm{L} \mathrm{Eu}$ in $3 \mathrm{M} \mathrm{HNO}_{3}$. The $K_{\mathrm{d}}$ values with the TBDGA - 
Table 6

Characteristics of the chromatographic resin materials and the corresponding packed column.

\begin{tabular}{lll}
\hline Parameter & TBDGA- $n$-dodecane resin & TBDGA-ionic liquid resin \\
\hline Average density & $1.53 \mathrm{~g} / \mathrm{mL}$ & $1.68 \mathrm{~g} / \mathrm{mL}$ \\
Resin packed in the column & $500.5 \mathrm{mg}$ & $500.3 \mathrm{mg}$ \\
Column dimension & $4.0 \mathrm{~mm} \times 240 \mathrm{~mm}$ & $4.0 \mathrm{~mm} \times 245 \mathrm{~mm}$ \\
Bed height & $7.5 \mathrm{~cm}$ & $7.2 \mathrm{~cm}$ \\
Bed volume & $3.77 \mathrm{~mL}$ & $3.62 \mathrm{~mL}$ \\
Bed density & $54.2 \mathrm{~g} / \mathrm{mL}$ & $61.5 \mathrm{~g} / \mathrm{mL}$ \\
Flow rate $(\mathrm{mL} / \mathrm{min})$ & 0.05 & 0.05 \\
Breakthrough volume & $8 \mathrm{~mL}$ & $7 \mathrm{~mL}$ \\
\hline
\end{tabular}

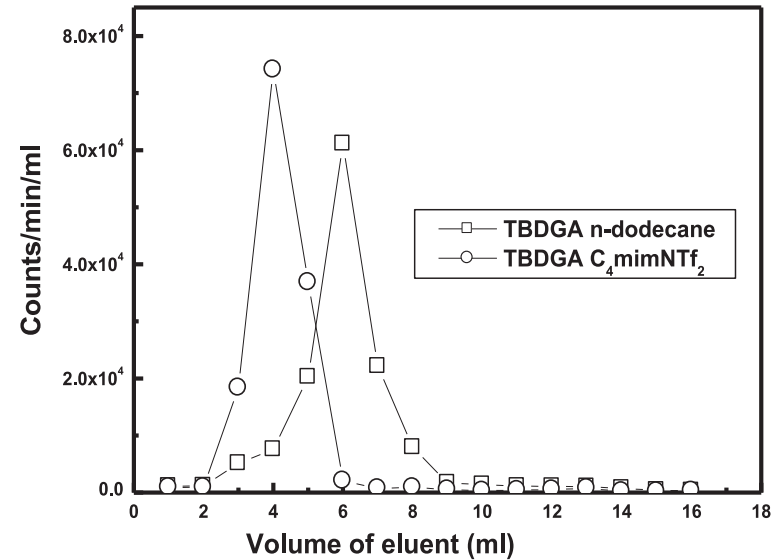

Fig. 8. Elution profiles for $\mathrm{Eu}(\mathrm{III})$ loaded onto the TBDGA resin columns. Eluent: 1 $\mathrm{M}$ guanidine carbonate $+0.05 \mathrm{M}$ EDTA in distilled water.

n-dodecane resin was $43.6 \pm 1.8$ while that with the TBDGA - ionic liquid resin was $37.9 \pm 1.2$ suggesting drastic decrease in the $K_{\mathrm{d}}$ values. Two observations are made from these results, firstly, the $K_{\mathrm{d}}$ values have drastically decreased due to loading effect and secondly, there is a reversal in the $K_{\mathrm{d}}$ values as compared to those seen from the tracer studies. As already mentioned, the column studies were not carried out using ${ }^{241} \mathrm{Am}$ in view of its very high specific activity and gamma ray dose.

After the columns were loaded with macro concentrations of Eu, spiked with ${ }^{152,154} \mathrm{Eu}$ radiotracer, the elution of the loaded metal ion was attempted using a mixture of $0.05 \mathrm{M}$ EDTA in $1 \mathrm{M}$ guanidine carbonate solution. Use of EDTA is justified due to its strong complexing ability with trivalent $f$-cations. It was interesting to note that the elution of the entire amount of $\mathrm{Eu}(\mathrm{III})$, loaded onto the column, was possible after passing ca. $7 \mathrm{~mL}$ of the stripping solution for the ionic liquid resin, while ca. $9 \mathrm{~mL}$ of the eluent was required for the $n$-dodecane resin column. The elution profiles of both the columns are depicted in Fig. 8. As seen from the figure, the elution peaks are sharp with almost no tailing. This suggests that the TBDGA resin-based columns can be successfully used for the separation of $\mathrm{Eu}(\mathrm{III})$ and will have a good application potential with environmental samples with very low amounts of the metal ion. As $\mathrm{Eu}(\mathrm{III})$ is considered as a surrogate of the trivalent actinide ions, the columns can be used for the separation and assay of actinides such as Am(III) in lean radioactive waste as well as environmental samples. The mass balance of the loaded $\mathrm{Eu}(\mathrm{III})$ and the eluted $\mathrm{Eu}(\mathrm{III})$ fractions was very well and was within $\pm 4 \%$.

\section{Conclusions}

Two TBDGA-based resins, one containing a molecular diluent (n-dodecane) and the other one an ionic liquid $\left(\mathrm{C}_{4} \mathrm{mim} \bullet \mathrm{NTf}_{2}\right)$, were prepared and tested for $\mathrm{Eu}(\mathrm{III})$ uptake from acidic feeds with a view to applications in radioactive waste or environmental samples. The ionic liquid-based resin was superior in terms of metal ion uptake and the $K_{\mathrm{d}}$ values of $\mathrm{Eu}(\mathrm{III})$ being larger than those obtained for Am(III), which is in line with DGA-based extractants. Overall, the metal ion uptake data are highly encouraging, even better than that with TODGA, though the multiple DGA extractantbased resins (as mentioned in Table 3 ) remain the most efficient. The selectivity (as measured by the uptake of Eu(III) vis-à-vis that of $A m(I I I)$ ) was found to be higher than those reported with other DGA / multiple DGA extractant resins, the $n$-dodecane based resin showing a higher selectivity than the ionic liquid resin.

The sorption isotherm data were fitted to various well known models such as Langmuir, Feundlich, D-R and Temkin. Monolayer sorption was found to be operating with chemisorption as the main factor for metal ion uptake by both the resins. The encouraging metal ion uptake data with the ionic liquid resin was supported by a very good reusability of the resin lasting for five cycles without any significant decrease in the uptake efficiency. The column studies showed good uptake and sharp elution peaks, suggesting that the resins can be used for the separation of trivalent lanthanide together with the trivalent actinide ions from radioactive waste / environmental samples.

\section{Declaration of Competing Interest}

The authors have no conflict of interest to declare.

\section{CRediT authorship contribution statement}

Rajesh B. Gujar: Methodology, Formal analysis. Akalesh G. Yadav: Methodology. Prasanta K. Mohapatra: Conceptualization, Writing - original draft. T.P. Valsala: Supervision. Darshan B. Sathe: Supervision. Raj B. Bhatt: Supervision, Project administration. Willem Verboom: Writing - original draft.

\section{Acknowledgement}

The authors thank Dr. P.K. Pujari, Head, Radiochemistry Division and Director, Radiochemistry \& Isotope Group for his constant encouragement.

\section{Supplementary materials}

Supplementary material associated with this article can be found, in the online version, at doi:10.1016/j.chroma.2021.461999.

\section{References}

[1] G.R. Choppin, A. Morgenstern, Radionuclide separations in radioactive waste disposal, J. Radioanal. Nucl. Chem. 243 (2000) 45-51.

[2] D.D. Sood, S.K. Patil, Chemistry of nuclear fuel reprocessing: Current status, J. Radioanal. Nucl. Chem. 203 (1996) 547-573.

[3] Characteristics of spent nuclear fuel and cladding relevant to high level waste source term, CNWRA-93-006. 
[4] W.W. Schulz, E.P. Horwitz, The TRUEX process and the management of liquid TRU waste, Sep. Sci. Technol. 23 (1988) 1191-1210.

[5] Y. Zhu, R. Jiao, Chinese experience in the removal of actinides from high active waste by trialkyl phosphine oxide extraction, Nucl. Technol. 108 (1994) 361-369.

[6] Y. Morita, M. Kubota, Research and development on the partitioning process at JAERI, J. Nucl. Sci. Technol. 24 (1987) 227-232.

[7] G. Modolo, H. Vijgen, D. Serrano-Purroy, B. Christiansen, R. Malmbeck, C. Sorel, P. Baron, DIAMEX counter-current extraction process for recovery of trivalent actinides from simulated high active concentrate, Sep. Sci. Technol. 42 (2007) 439-452.

[8] S.A. Ansari, P.N. Pathak, P.K. Mohapatra, V.K. Manchada, Chemistry of diglycolamides: Promising extractants for actinide partitioning, Chem. Rev. 112 (2012) $1751-1772$.

[9] O.B. Mokhodoeva, G.V. Myasoedova, E.A. Zakharchenko, Solid-phase extractants for radionuclide pre-concentration and separation. New possibilities, Radiochemistry 53 (2011) 35-43.

[10] I. Akaza, in: T. Braun, G. Ghersini (Eds.), Extraction Chromatography, Elsevier, NY, 1975 (p. 17).

[11] S.A. Ansari, P.K. Mohapatra, A review on solid phase extraction of actinides and lanthanides with amide based extractants, J. Chromatogr. A 1499 (2017) 1-20.

[12] E.P. Horwitz, D.R. McAlister, A.H. Bond, R.E. Barrans, Novel extraction of chromatographic resins based on tetraalkyldiglycolamides: characterization and potential applications, Solvent Extr. Ion Exch. 23 (2005) 319-344.

[13] S.A. Anasari, P.N. Pathak, M. Husain, A.K. Prasad, V.S. Parmar, V.K. Manchanda, Extraction chromatographic studies of metal ions using $N, N, N^{\prime}, N^{\prime}$-tetraoctyl diglycolamide as the stationary phase, Talanta 68 (2006) 1273-1280.

[14] K. Van Hecke, G. Modolo, Separation of actinides from low level liquid wastes (LLLW) by extraction chromatography using novel DMDOHEMA and TODGA impregnated resins, J. Radioanal. Nucl. Chem. 261 (2004) 269-275.

[15] M. Husaina, S.A. Ansari, P.K. Mohapatra, R.K. Gupta, V.S. Parmar, V.K. Manchanda, Extraction chromatography of lanthanides using $N, N, N^{\prime}, N^{\prime}$-tetraoctyl diglycolamide (TODGA) as the stationary phase, Desalination 229 (2008) 294-301.

[16] R.B. Gujar, P.N. Pathak, G.B. Dhekane, P.K. Mohapatra, Extraction of some hexavalent actinide ions from nitric acid medium using several substituted diglycolamides, Solvent Extr. Ion Exch. 32 (2014) 637-649.

[17] T. Welton, Room-temperature ionic liquids. Solvents for synthesis and catalysis, Chem. Rev. 99 (1999) 2071-2083.

[18] K. Binnemans, Lanthanides and actinides in ionic liquids, Chem. Rev. 107 (2007) 2592-2614

[19] P.K. Mohapatra, Actinide ion extraction using room temperature ionic liquids: opportunities and challenges for nuclear fuel cycle applications, Dalton Trans 46 (2017) 1730-1747.

[20] R.D. Rogers, K.R. Sheddon, Ionic liquids: solvents for the future? Science 302 (2003) 792-793.

[21] X. Sun, H. Luo, S. Dai, Ionic Liquids-Based Extraction: A Promising Strategy for the Advanced Nuclear Fuel Cycle, Chem. Rev. 112 (2012) 2100-2128.

[22] P.R. Vasudeva Rao, K.A. Venkatesan, A. Rout, T.G. Srinivasan, K. Nagarajan, Potential Applications of Room Temperature Ionic Liquids for Fission Products and Actinide Separation, Sep. Sci. Technol. 47 (2012) 204-222.

[23] M.T. Friend, T.G. parker, T. Mastren, V. Mocko, M. Brugh, E. R. Birnbaum, M.E. Fassbender, Extraction chromatography of 225Ac and lanthanides on N,N-dioctyldiglycolamic acid /1-butyl-3-methylimidazolium bis(trifluoromethylsulfonyl)imide solvent impregnated resin, J. Chromatogr. A 1624 (2020) 461219.

[24] R.B. Gujar, S.A. Ansari, P.K. Mohapatra, A. Leoncini, W. Verboom, Solid phase extraction of $\mathrm{Am}(\mathrm{III})$ and $\mathrm{Cm}(\mathrm{III})$ from acidic feeds using tetraethyl diglycolamide (TEDGA) in ionic liquid, J. Radioanal. Nucl. Chem. 309 (2016) 819-825.

[25] J. Mendham, R.C. Denny, J.D. Barnes, M. Thomas, B. Sivasankar, in: Vogel's textbook of quantitative chemical analysis, sixth edition, Pearson Education Ltd, New Delhi, 2009, pp. 332-335.

[26] P.K. Mohapatra, S. Sriram, V.K. Manchanda, L.P. Badheka, Uptake of metal ions by extraction chromatography using dimethyl dibutyl tetradecyl-1,3-malonamide (DMDBTDMA) as the stationary phase, Sep. Sci. Technol. 35 (2000) 39-55.
[27] K.L. Nash, A review of the basic chemistry and recent developments in trivalent f-elements separations, Solvent Extr. Ion Exch. 11 (1993) 729-768.

[28] A. Bhattacharyya, P.K. Mohapatra, Separation of trivalent actinides and lanthanides using various ' $\mathrm{N}$ ', 'S' and mixed ' $\mathrm{N}, \mathrm{O}$ ' donor ligands: a review, Radiochim. Acta 107 (2019) 931-949.

[29] Y. Sasaki, Y. Sugo, S. Suzuki, S. Tachimori, The novel extractants, diglycolamides, for the extraction of lanthanides and actinides in $\mathrm{HNO}_{3}$-n-dodecane system, Solvent Extr. Ion Exch. 19 (2001) 91-103.

[30] G. Prasad, K. Muralidhar Reddy, R. Padamasuvarna, T. Madhu Mohan, T. Vijaya Krishna, V. Ramesh Kumar, Thermophysical properties of 1-butyl-3-methylimidazolium bis (trifluoromethylsulfonyl) imide with 2-ethoxyethanol from $T=(298.15$ to 323.15$) \mathrm{K}$ at atmospheric pressure, J. Mol. Liq. 251 (2018) 335-344.

[31] C. Kimble, C.M. Burba, Liquid structure of bis(trifluoromethylsulfonyl)imide-based ionic liquids assessed by FT-IR spectroscopy, J. Phys. Chem. B 121 (2017) 3099-3110.

[32] S. Wang, J. Liu, L. Yuan, Z. Cui, J. Peng, J. Li, M. Zhai, W. Liu, Towards understanding the color change of 1-butyl-3-methylimidazolium bis(trifluoromethylsulfonyl) imide during gamma irradiation: an experimental and theoretical study, Phys. Chem. Chem. Phys 16 (2014) 18729-18735.

[33] M. Sypula, A. Ouadi, C. Gaillard, I. Billard, Kinetics of metal extraction in ionic liquids: $\mathrm{Eu}^{3+} / \mathrm{HNO}_{3} / / \mathrm{TODGA} /\left[\mathrm{C}_{1} \mathrm{C}_{4} \mathrm{im}\right]\left[\mathrm{Tf}_{2} \mathrm{~N}\right]$ as a case study, RSC Adv 3 (2013) 10736-10744.

[34] G. Yu, D. Zhao, L. Wen, S. Yang, X. Chen, Viscosity of Ionic Liquids: Database, Observation, and Quantitative Structure-Property Relationship Analysis, AIChE J, 58 (2012) 2885-2899.

[35] R.B. Gujar, S.A. Ansari, P.K. Mohapatra, Spectacular enhancements in actinide ion uptake using novel extraction chromatography resins containing TODGA and ionic liquid, Sep. Purif. Technol. 141 (2015) 229-234.

[36] R.B. Gujar, S.A. Ansari, W. Verboom, P.K. Mohapatra, Multi-podant diglycolamides and room temperature ionic liquid impregnated resins: An excellent combination for extraction chromatography of actinides, J. Chromatogr. A 1448 (2016) 58-66.

[37] S.A. Ansari, P.K. Mohapatra, M. Iqbal, J. Huskens, W. Verboom, Two novel extraction chromatography resins containing multiple diglycolamide-functionalized ligands: Preparation, characterization and actinide uptake properties, J. Chromatogr. A 1334 (2014) 79-86.

[38] M.P. Jensen, T. Yaita, R. Chiarizia, Reverse-micelle formation in the partitioning of trivalent f-element cations by biphasic systems containing a tetraalkyldiglycolamide, Langmuir 23 (2007) 4765-4774.

[39] K. Nakashima, F. Kubota, T. Maruyama, M. Goto, Feasibility of Ionic Liquids as Alternative Separation Media for Industrial Solvent Extraction Processes, Ind. Eng. Chem. Res. 44 (2005) 4368-4372.

[40] I. Langmuir, The constitution and fundamental properties of solids and liquids, J. Am. Chem. Soc. 38 (1916) 2221-2295.

[41] H.M.F. Freundlich, Über die Adsorption in Lösungen, Z. Physik. Chemie 57A (1906) 385-470.

[42] A. El Nemr, Potential of pomegranate husk carbon for $\mathrm{Cr}(\mathrm{VI})$ removal from wastewater: Kinetic and isotherm studies, J. Hazard. Mat. 161 (2009) 132-141.

[43] M.M. Dubinin, The potential theory of adsorption of gases and vapors for adsorbents with energetically non-uniform surfaces, Chem. Rev. 60 (1960) 235-241.

[44] D.M. White, T.A. Pilon, C. Woolard, Biological treatment of cyanide containing wastewater, Water Research 34 (2000) 2105-2109.

[45] M. Polanyi, Theories of the adsorption of gases. A general survey and some additional remarks, Trans. Faraday Soc. 28 (1932) 316-333.

[46] S. Kundu, A.K. Gupta, Investigation on the adsorption efficiency of iron oxide coated cement (IOCC) towards As(V) - kinetics, equilibrium and thermodynamic studies, Colloids Surf. A 273 (2006) 121-128.

[47] S. Panja, P.K. Mohapatra, S.C. Tripathi, G.D. Dhekane, P.M. Gandhi, P. Janardan, Liquid - liquid extraction and pertraction of $\mathrm{Eu}(\mathrm{III})$ from nitric acid medium using several substituted diglycolamide extractants, Sep. Sci. Technol. 48 (2013) 2179-2187. 